\title{
The Role of Physical Education Instructors Towards Effective Sports Management in Nigeria Primary Schools
}

\author{
Ugwu Jude Ikechukwu, Dr. Ben Ohuruogu \\ Ebonyi State University, Abakaliki, Ebonyi State \\ Ogazi Precious Chioma \\ Department Of Primary Education, School Early Childhood And Primary Education Federal College Of \\ Education (Technical) Asaba \\ Ibe Ijeoma Maria Assumpta \\ Department of General Study, Federal College of Education (Technical) Asaba. Delta State
}

\begin{abstract}
The paper focused on physical education from pre-colonial time to present day in Nigeria and recommended some changes to remedy observed problems encountered in physical education in the past. The post-independence curriculum reform movements led to the 1969 curriculum conferences which prescribed better diversified curriculum, and recommended the inclusion of physical education as an instructional subject especially in primary schools. The National Policy on education 1977 revised in 1981 recognized the status of physical education instructors, and identified quality and benefits of teaching physical education especially in primary schools and it also addresses physical education instructor's roles for effective management of sports, official code of conduct including various steps to be adopted for successful physical education activities in our schools. Finally, the paper recommended some of the following for the good conduct of physical education activities, in our schools such as creating enough time for physical education and sports in the school timetable and curriculum, and provision of adequate resources such as facilities, equipment as this will help to influence the attitudes of the students towards sports participation.
\end{abstract}

Keywords: National Policy on Education, Physical Education, Primary School, Instructors

DOI: $10.7176 / \mathrm{JEP} / 10-24-06$

Publication date: August 31st 2019

\section{Introduction}

Physical education in primary schools is emerging as the art and science of human movement. Quality elementary school programmes and teachers seek to instill in children the why of movement. The how of movement and the outcomes or physiological, psychological, and sociological results of movement. A primary objective of these programs is the sound development of movement skills and motor patterns that make up the movement repertoire of human beings. Providing a quality physical education programmes for young children is critical. Participation in a quality programme during these formative years will likely instill in the child a love for physical activity that may last a lifetime and favourable attitude toward physical education. If the experience is negative, the youngsters may come to hate physical education as well as physical activity, a feeling that could remain with him or her for life. Because of the close relationship between physical activity and health, this could have a significant impact on the quality of the child's life.

Physical education involves the holistic development of an individual through four channels of human development. Physical education as an instrument for pattern maintenance, goal attainment, social integration and tension management. Coaldey (1994). Since the existence of man, nations and people have always engaged in one form of physical education or the other. According to Momodu (1998), physical exercises have served man faithfully and unselfishly right from pre-historical time. As mankind developed, the role of physical education instructors has grown and its responsibilities increased at many levels especially primary schools.

Movement experiences are recognized as educationally desirable in the early life of the child. This is the time when a solid movement foundation can be developed providing children with a base for future physical development and achievement in various forms of physical activity. Furthermore, it is through movement that children express themselves, and also, physical education programmes provide physical health benefits for children which leads to more alertness in the classroom (Pangrazi and robber 2007). Develop self-image and gain a better understanding of their physical selves. It is through such movement experiences that young children explore, development and grow in meaningful manners.

In the primary schools great emphasis is placed on learning fundamental motor skills such as running, jumping climbing, throwing, catiling, kicking and striking. Children participate in guided discovery and problem-solving activities focused on movement concepts, including body awareness, spatial awareness, qualities of movement and relationships. Conceptually based programmes further enhance the child's understanding of movement. 
Perceptual-motor activities help children to develop such necessary skills as eye hand and eye-foot co-ordination, laterality and directionality, and tracking of an object.

According to Adedeji (1985), physical education which was introduced into Nigerian schools around 1900's resembled that of the $17^{\text {th }}$ and $18^{\text {th }}$ centuries, by Britain, had previously been influenced by both German and Swedish systems. The main objective of this inherited physical education programme was to prepare youths for war. At that time, Nigeria was at war and thus the programme was not tailored to meet their needs. Adedeji (1985) observed that instead of improving indigenous activities, which could help in solving local and national problems, emphasis on physical education was placed on their system to prepare Nigerians mainly for competitive sport. He noted that these preparations aided Nigeria's participation in the first and second world wars.

It is important to mention that physical education was not completely alien to Nigeria as other countries of the world. The traditional method of obtaining physical fitness was achieved through manual labour, and communal recreation with local games like Warri game (Ayo), Draft, ido and Marbles (Arin) Okoto etc. Adedeji (1985). Schools at this time were generally limited in their objectives. These severe limitations were not peculiar to physical education. The deficiencies were due to the fact that the schools were established for Christian evangelization purposes. Consequently, the curriculum understandably consisted of the four Rs, and reading materials were provided from the chapters of the Bible (Nwagwu, 1976). Under such a situation, physical education was de-emphasized if not retarded as was the case during the Dark ages.

Later, there was little ray of hope for curriculum improvement with the introduction of 1926 education code. This became first of its kind in Nigeria as it categorized the school system into infant, primary, secondary levels of education and teacher's training inclusive (NPE 1977). Inspite of the observed improvement in curriculum programmes, physical education was again conspicuously absent from the primary school curriculum. It recommended elements of reading, writing, numbering, eye and hand training, nature study, hygiene and religious study as subjects of instruction in primary schools (NPE 1977). Which was the transfer of the outworn British traditional system to Nigeria. Again, the 1926 education code failed to meet the needs of Nigeria at the period under review, because it was not designed to promote the optimal growth of the child and stimulate rapid national development.

The second school curriculum also showed visible deficiencies among which was the exclusion of physical education from the curriculum. According to (NPE 1981), not only was the range of subjects narrow but again, as in the primary school, the subjects offered were often not related to the Nigerian needs and conditions. Happily, the document prescribed physical and Health Education into the Higher Elementary (Grade II Teachers Curriculum). An Advanced physical and Health Education course was also incorporated into the curriculum at this level for highly skilled students. Both were to be internally examined while the later was merely an elective.

At the tertiary level, physical education was not taught at all until the Nigerian College of Arts, Science and Technology; Zaira which later meta-morphosed into Ahmadu Bello University, mounted a three year Diploma course in Physical Education. This institution produced most pioneer in physical education in Nigeria. Noteably most physical education specialists were also trained overseas principally Britain and later United States of American and Canada. It was obvious that physical education as an instructional subject was non-existence in both primary and secondary school levels of education. It only featured as sports and games, which were largely unschematized.

The curriculum reform movements in Nigeria began in the pre-independence and heightened on postindependence era. These efforts materialized in 1970's partly in the form of the National policy on Education (NPE, 1981) which ushered in a new era of positive growth of physical education. In the 1969 curriculum conference, Obiogun (1969) and Elegbe (1969) prescribed subject additions and a diversified curriculum for all levels of education that could produce "the educated individual". They recommended the inclusion of physical education to be taught in all its phases in schools. This new status generated much enthusiasm and some policies were therefore formulated to guide performance which were spelt out on the National policy on Education. They are (i) The quality of instruction of all levels has to be oriented towards promoting Emotional, Physical and Psychological wellbeing of all children (ii) the government will increase the supply of specialist teachers for physical education (NPE 1981). The policy and document also listed physical education as core subject at the Junior Secondary School and an elective course at the senior secondary level. These achievements were due to unanimous demands of NAPHER.SD members principally Adedeji (1980), Amuchie (1972), Omeruan (1976) and others.

These policies lead to the, (i) establishment of physical education divisions in Ministries of Education (ii) physical and health education have been separated as two degree option to facilitate in-depth study of both subjects at the University level (iii) Development of a national physical education curriculum for both senior and junior secondary schools. (iv) Recruitment of specialist physical education teachers to facilitate the implementation of the programme. (v) Production of learning materials in physical education by government agencies such as National Teachers Institute and Nigeria Education Research and Development Council.

The primary school curriculum is concern with developing within each child a positive self image as a mover. 
Attention also should be given to developing desirable social skills such as working with others. The physical education curriculum focuses on refining fundamental motor skills and applying this skills to the development of sports related skills. During this time, all children should be given the opportunity to participate in a wide range of sports and physical activities rather than be encouraged to specialize in a few selected sports. Acquisition of knowledge relative to physical education and the development of qualities of good sportsmanship, leadership and fellowship should be encouraged.

\section{Benefits of quality Physical Education/Sports Programs to School Children}

There has been unprecedented support for physical Education and Sports from a number of sources outside of the school system. Medical experts recommend daily physical activity as an important means of preventing coronary health problems, such as, obesity, high blood pressure etc. Nutritionist prescribe a combination of diet and exercise for weight control. Mental Health Experts encourage physical activity as a means for releasing tension. Recreation leaders use sports and games to fill leisure hours, to release stress and to relax Solan (2010). Based on this support from these experts, and partially because of their contributions, the country seem to be experiencing little or no growth in the popularity of walking, running, aerobics, weight training, and a host of other activities, in particular for young and middle ages.

At the same time, lack of trained physical education-teachers (inadequacies in quality of teachers), tight budgets, and the attention given to physical education by schools, inadequate facilities, and lack of equipment and literature contributed to lack of improvement in Physical Education programmes

Parents and the general public to some extent are relatively unaware of the many positive changes which can occur as a result of participating in physical activities. Better communication is necessary among physical educators and those who support education and make curriculum decisions. Without improved communication, the feeling that physical education is a kind of play period for school children to run off steam and learn traditional team sports will continue to exist.

The curriculum expert have consistently maintained that physical-education makes valuable contribution to school children at all grade levels, primarily in the psychomotor domain, and also in the cognitive and affective areas. It is becoming more apparent with each passing year that school programs must help school children develop a vigorous healthy life-style, which include appropriate activities and attitudes for all stages of life. The benefits are:

* School children display positive attitudes towards an active life style.

* Exhibit better health habits (tend not to smoke).

* School children develop personal physical fitness and enhance bone growth.

* Exhibit more positive attitudes about school, physical activity and self.

* Play better with others

* Have less aggressive behaviours

* Perform as well or better academically.

\section{Concept of Physical Education Instructors}

They should be a designation which should have been given to those who have been trained in sports and physical education fields with a minimum of first degree (David 2007). Instructors should be by role policy makers in planning, directing, supervising, analyzing, leading and evaluation of sports matters in schools. They must have acquired sports management knowledge/skills and possess leadership qualities to allow proper monitoring.

Physical education instructors must be able to bring control to chaos, understand fairness, promote safety and encourage good sports-manship. They must have the positive characteristics of a police officer, lawyer, Judge, accountant, reporter, athlete and diplomat. They are someone who can be put in a position of authority and handle the responsibility without being over bearing.

Physical Education Instructors along with the rules of the game must fully understand his/her role before, during and after the game has ended. Muktar (2015) enumerated what physical educators should possess as Trustworthy, honesty and impartial; Responsible, and have integrity, and take the role seriously; prepared for their role, prepared physically and mentally for the task.

Muktar (2015) added the official's code of conduct by physical education instructors as:

- Place the safely and welfare of players and athletes above all else.

- Show concern and caution towards sick and injured players and athletes

- Be impartial consistent, objective and courteous when making decisions.

- Accept responsibility for any actions and decisions.

- Condemn unsporting behaviour and promote respect for the individuality of players and athletes.

- Avoid any situations which may lead to or be constructed as a conflict of interest.

- Be a positive model in behaviour and personal appearance and ensure any comments are positive and 
supportive.

- Be a good sport as I understand that actions speak louder than words.

- Always respect, remain loyal to and support other officials.

- Keep up to date with the latest laws of the game tends and principles of their application.

- Refrain from any form of personal abuse towards players or other officials.

- Respect the rights; dignity and worth of all people involved in the game regardless of their gender, ability or cultural background.

Seven major steps for the success of physical education instructor in our schools as suggested by Parks and Sun (2001), in our schools includes:

1. Keep your perspective: Right now, your most important goal is being a good official for whatever sport you are officiating. By studying, observing and practicing you will improve, just as the players do when they practise. Remember, it's a game for the players. Help them have fun.

2. Prepare for the unexpected: Take time before each game to talk with your partners about responsibilities. Meet at least 15 minutes before the start of your game and go over the local ground rules and any special interpretations or concerns that might exist concerning the teams involved. Don't leave any doubts unresolved with your partners.

3. Remember, you're in charge: When dealing with coaches or parents who can't control themselves in front of the players, you do not have to "take it" as much as officials at other levels. There are ways to handle verbally abusive coaches, players/athletes and spectators. See the game management" learning area for more information. Remember too that you're out there to control the game first and foremost, and to administer it within the framework of the rules.

4. Legal responsibilities and risk Management: As an official, you have a responsibility to ensure that all games are conducted in a safe environment. Do not let a coach intimidate you into beginning or continuing a game when rain, fog, lightning, wet floors, leaking roofs or other problem condition exist. When in doubt, use common sense and err on the side of safety.

5. Climb the ladder at your own peace: Sports need officials, if you become a good official with younger players and athletes, there will be opportunities for you to move up the age grades- if you want, it's up to you just how far you want to go. Just go at a pace that makes you comfortable.

6. Keep your focus: Remember with each age level increase the games, become more competitive and skill levels improve. Still, kids will be kids and mistakes of every kind can happen. You must be able to concentrate, know that if you're not focused, you risk losing control of the game.

7. Humble thyself: No matter how good you think you are, you're only as good as you last call. Once your game is over, it's history. You should learn from it and take those lessons with you into the next game.

\section{Concept of Sports Management}

Sports management is a rapidly growing area of knowledge, it involves directing, planning, managing and coordinating programme, human material and physical resources in sports organizations. (Parks and Sun 2001) defined sports management as way combination of skill related to planning, organizing, controlling, budgeting, leading and evaluating within the context of an organization or services is related to sport and or physical activity. Sports management however in this work means efforts by physical education instructors in, planning, directing, managing, organizing and coordinating physical education programme, human material and physical resources in schools. Desensi, Kelley, Blanton, and Beitel (1990), defined sports management as any combination of skills related to planning, organizing, directing, controlling, budgeting, leading and evaluating within the context of an organization or department whose primary product is related to sport.

Roles of Physical Education Instructors Towards Effective Sports Management in Nigeria Primary Schools

1. Physical Education Instructors must have access and understand very well the goals, philosophy and objectives of their sports establishment. The aim of organized physical education and sport programme is to create an environment that stimulates selected movement experiences resulting in desirable response that contribute to the optimal development of the individual's potentialities in all phases of life. The objectives of the school physical education and sports is to provide schools for development students achieve a healthenhancing life of physical activity, understand and respect individual differences among peoples in physical settings, integrate Physical Education and Sports into primary school curriculum, provide for a safe physical environment, provide students with a variety of activities that will enhance life-long learning and participation, and promote physical excellence.

The philosophy, are that regular physical activity provides numerous health benefits-from learner bodies and lower blood pressure to improved mental health and cognitive functioning. Physical Education Instructors must be always ready to explain and defend them whether they find themselves in local government, state, national or international engagements. 
2. They must be always satisfying in carrying out their monitoring and supervisory scheduled: Responsibilities of handling the establishment, correspondences, travelling arrangements for players/athletes, coaches and the accompanied officials, local, state, nationals and international. He should always ensure that the competition's facilities and equipment are provided in time and where not available necessary explanation is given to convince those concerned. Those available should be well managed always.

3. The Physical Education Instructor should be publicity conscious and relate very well with media and others to be able to create right environment for sports promotion and marketing, in order to attract sponsors. There should be local and national coverage of school sports. Newspaper and print media should be used to provide appropriate space and publicity for the program and its activity.

4. The Physical Education Instructors should give appropriate directions and arrangement of meetings of the board members on appointed dates, time and venue. The writing of minutes represent the general discussions, resolutions and decisions taken with-out bias. They should also guide the members on the government polices as they effect the decision they are to take to prevent conflicts in management.

5. The Physical Education Instructors should recognized the class size. Classes in physical education should be approximately the same size as classes in other subjects offered in school. This is as essential for effective teaching, in individualized instruction, and optimal performance in physical education as it is other content subjects. Physical education contributes to educational objectives in an equal basis with other subjects in the curriculum.

6. The Physical Education Instructors must recognize that finance is the most fundamental concern of every successful management, the same it is with sports management. Financial allocateion should be made for each local governments and states for sports development. Pupils should also pay a fee for sports development in their respective schools Accommmodation, feeding, transportations, medical care, competition, registration fee and allowance of the athletes, coaches and accompanied officials should not be interfered with since that usually results to serious management crisis.

7. The physical education instructors should play a leadership role in the development of the school physical activity programme, the increase in the number of overweight children and the decrease in physical activity time in school make for a national problem. Curtailing this national epidemic can be addressed at a local level, and the physical instructor must be the "go-to" person to promote change in the schools.

8. They should teach students skills and activities that translate into physical activity outside of physical education class, learned physical education class, transfer to skills used in a child's play.

9. They motivate children to be active. There are many ways to do this, including promoting community activities, assigning physical activity homework or home fun, showing an interest in the out-of class physical activity in which children participate and leading by example.

10. They also have the responsibility to help direct and guide opportunities for physical activity in the school and outside the physical education class.

\section{Summary}

Physical education in primary schools is emerging as the art and science of human movement. Quality primary school programmes and teachers seek to instill in the children the why of movement, the how of movement and the outcomes of physiological psychological and sociological results of movement. The primary objectives of this programme is the sound development of human skills and motor patterns that make up the movement repertoire of human beings. Therefore providing a quality physical education programme for yong children in crucial. The primary school curriculum is concerned with developing within each child a positive self image as a mover. Attention should also be given to developing desirable social skills such as working with others, and acquisition of knowledge relative to physical education and the development of qualities of good sportsmanship, leadership and fellowship should be encouraged. Physical education instructors must have access and understand very well the goals, philosophy and objectives of their sports establishment. The basic facts remains that physical educations as a profession remains one of the most important in the development of physical, mental, social and spiritual development of the child and sports of any nation and local government in particular.

\section{Recommendations}

For the physical education instructors to achieve success. The following administrative and official's code of conduct actions should be observed.

1. Re-structuring the designation of sports management staff by local and state civil service commission. They should ensure that those who have sports and physical education related training should only be appointed to management positions as games masters/mistress, physical instructors, local government sports schedule officers and sport officers. Sports officer in the local government can also be promoted up to chief sports officer and Directors of Sports but all to have specific management roles.

2. Creation of the full department/ units for physical education and sports in schools, local government education 
Authority and state primary education boards.

3. Creating enough time for physical education and sports in school timetable and curriculum.

4. Provision of adequate physical resources including facilities, equipment and maintenance. This will help $n$ influencing attitudes and facilitating program successfully.

5. The instructional loads and staffing of the physical educator should be a prime concern to management. To maintain a high level of enthusiasm, vigour and morale, it is important that the load be fair and equitable.

6. Quality instructional programmes which provides opportunities for each child to develop motor skills and efficient movement patterns should be encouraged by all and sundry.

\section{References}

Adedeji, J.A (1985). The Teaching of Physical and Health Education, Ibadan: West Books Publishers Limited.

Coaldey J.J (1994). Sports in Society, Issue and Controversies, Mosby Publising Co.

David, C.W. (2003). Sports Management and Administration. E \& FN SPON. U.S.A

Dlegbe, R.A. (1969). Education for living in Adeniyi Adaralegbe (Eds). A Philosophy for Nigerian Education Proceedings of National Curriculum Conference 8-12 September 1969, Ibadan, Heinemann Books Nigeria.

Federal Ministry of Education (1977). National Policy on Education, Lagos

Federal Ministry of Education (1981). National Policy on Education, Lagos.

Muktar, S.B. (2015). Sports management in Perspective. Flash Printers, Kano.

Momodu, A. (1998). An Analysis of the Primary School Physical Education Curriculum in Edo State in Press.

Nwagu, N.A. (1976). UPE Issues, Prospects and Problems, Benin, Ethiopia Publishing.

Parks, J.B. \& Sun, J (2001). Ex-sport II: An Artificial Intelligence Sport. Management Career guidance system. http://presonal.bgsu.eud/-Jparks/Esport/

Densensi, J., Kelley D, Blanton M, and Beitel P. (1990). Sport Management Curricular evaluation and needs assessment: a multifaceted approach, Journal of sports management 4(1): 31-58.

Slon, S. (2010). The continuing development of Primary Sector Physical Education Working together to raise quality of provision. European Physical Education. Review 16 (3) pages 267-281.

Wuest, D.A. and Bucher, C.A. (2006). Foundations of physical education, exercise science and sport ( $5^{\text {th }}$ Ed.). The McGraw-Hill companies.

Daley, J. (2007). "Academic performance and participation in physical activity by primary school” perceptual and motor skills ( $\left.3^{\text {rd }} \mathrm{Ed}\right)$ 531-534. 